\section{Accepted Manuscript}

This article can be cited before page numbers have been issued, to do this please use: A. V. Mirco, M. Benaglia, S. Rossi, T. Benincori, R. Cirilli and M. Pierini, Org. Biomol. Chem., 2019, DOI:

\section{Organic \& Biomolecular Chemistry}

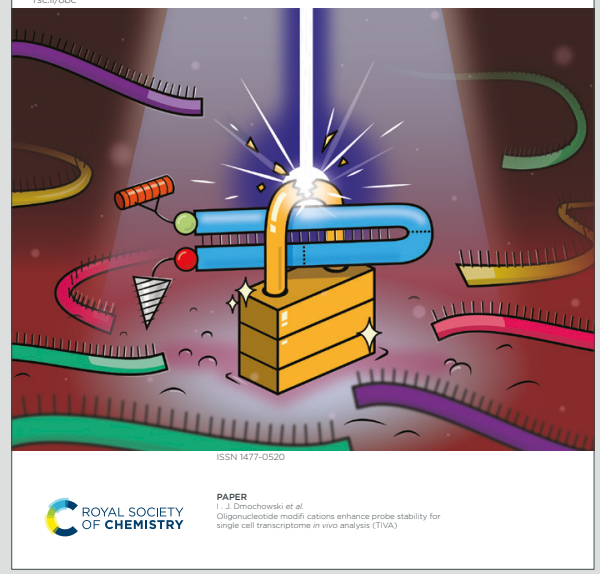

This is an Accepted Manuscript, which has been through the Royal Society of Chemistry peer review process and has been accepted for publication.

Accepted Manuscripts are published online shortly after acceptance, before technical editing, formatting and proof reading. Using this free service, authors can make their results available to the community, in citable form, before we publish the edited article. We will replace this Accepted Manuscript with the edited and formatted Advance Article as soon as it is available.

You can find more information about Accepted Manuscripts in the Information for Authors.

Please note that technical editing may introduce minor changes to the text and/or graphics, which may alter content. The journal's standard Terms \& Conditions and the Ethical guidelines still apply. In no event shall the Royal Society of Chemistry be held responsible for any errors or omissions in this Accepted Manuscript or any consequences arising from the use of any information it contains. 
Received 00th January 20xx, Accepted 00th January 20xx DOI: $10.1039 / \times 0 \times x 00000 x$

\title{
TetraPh-Tol-BITIOPO: a new atropisomeric 3,3'-bithiophene based phosphine oxide as organocatalyst in Lewis Base-catalyzed Lewis Acid mediated reactions.
}

\author{
Abbinante Vincenzo Mirco, ${ }^{a}$ Benaglia Maurizio, ${ }^{b}$ Rossi Sergio, ${ }^{\text {b }}$ Benincori Tiziana, ${ }^{\text {*a }}$ Cirilli Roberto, \\ Pierini Marco. ${ }^{d}$

\begin{abstract}
A new chiral phosphine oxide based on 3,3'-bithiophene scaffold (tetraPh-Tol-BITIOPO) was synthesized, fully characterized and separated into antipodes through chiral HPLC. This new compound was successfully employed as organocatalyst in Lewis base-catalyzed Lewis acid mediated reactions involving trichlorosilyl compounds. The new atropisomeric catalyst was able to promote the allylation of aldehydes with allyltrichlorosilane in up to $98 \%$ yield and up to $96 \%$ enantiomeric excess (ee), and the direct aldol reaction to afford $\beta$-hydroxy ketones and $\beta$-hydroxy thioesters, with good chemical yields and modest stereochemical efficiency. Computational studies helped to elucidate and to rationalize the stereochemical outcome of the reactions catalyzed by TetraPh-Tol-BITIOPO, that was found to favour the formation of the isomer with the opposite absolute configuration in comparison with the products obtained with the previously reported 3,3'-bithiophene-based catalyst.
\end{abstract}

\section{Introduction}

The development of new chiral catalysts able to perform stereoselective chemical transformation is a topic of great interest, since it represents one of the best opportunities to introduce stereogenic centers into organic molecules. In this field, Lewis bases represent one of the most investigated classes of compounds that has found application in a large number of chemical transformations thanks to their strong versatility and applicability. ${ }^{1}$ Moreover, due to their unique properties, Lewis bases have found applications also in the so called Lewis basecatalyzed Lewis acid-mediated reactions, a class of reactions where the Lewis base acts as activator of a weak Lewis acid (generally a silicon-based compound), leading to the formation of a new hypervalent adduct ${ }^{2}$ able to promote different chemical transformations. ${ }^{3}$ A milestone in this field was reported by Kobayashi in 1993, describing for the first time a stereoselective allylation of aldehydes using allyltrichlorosilanes activated by dimethylformamide. ${ }^{4}$ On the basis of this work, many examples of diastereo- and enantioselective transformations involving the use of chiral Lewis bases for the activation of trichlorosilane, allyltrichloro silane and silicon tetrachloride were developed. ${ }^{5}$ In this sense, optically pure $\mathrm{N}$-formyl derivatives, picolinamides, $\mathrm{N}$-oxides and sulfoxides, sulfinamides ${ }^{6}$ have found great application as

a Dipartimento di Scienza ed Alta Tecnologia dell'Università dell'Insubria, Via Valleggio 11, 22100 Como, Italy.

${ }^{b}$ Dipartimento di Chimica, Università degli Studi di Milano, Via Golgi 19, 20133 Milano, Italy.

c Centro Nazionale per il Controllo e la Valutazione dei Farmaci, Istituto Superiore di Sanità,Viale Regina Elena 299, 00161 Roma, Italy.

${ }^{d}$ Dipartimento di Chimica e Tecnologie del Farmaco, Università degli Studi di Roma "La Sapienza”, Piazzale Aldo Moro 5, 00185 Roma, Italy

Electronic Supplementary Information (ESI) available: [details of any supplementary information available should be included here]. See DOI: 10.1039/x0xx00000x chiral organocatalysts toward stereoselective $\mathrm{C}-\mathrm{N}$ and $\mathrm{C}-\mathrm{O}$ double bond reductions, ${ }^{6-7}$ whereas phosphoramides ${ }^{8}$ and phosphine oxides ${ }^{9}$ have been employed mostly for stereoselective C-C bond formation reactions. ${ }^{8 k, 10}$

Although several mono and bis phosphoramides with different geometries have been developed, examples of phosphine oxides were essentially related to the use of bis(diphenylphosphinoyl)-binaphthyl dioxide (BINAPO) and its modified versions. ${ }^{9 i, 11}$ In order to expand this field, our group reported for the first time the synthesis and the use of a more electron rich phosphine oxide, based on 3,3'-bithiophene scaffold $^{12}$ that showed improved performances compared to BINAPO catalyst. ${ }^{13}$ Following our strategy, other different phosphine oxides were then reported, such as the spiro[4,4]1,6-nonadiene-based diphosphine oxide, ${ }^{9 d}$ the atropoisomeric $(Z, Z)-2,3-$ bis[1-(diphenylphosphinyl)ethylidene]tetralin, ${ }^{14}$ and also bisphosphine oxides containing an allene backbone. ${ }^{15}$ Phosphine oxides based on Taddol scaffold, ${ }^{16}$ on aziridinyl moiety ${ }^{17}$ or on bis(triazolyl) backbone ${ }^{18}$ were also recently described. Unfortunately, some of these catalysts, despite their great stereochemical efficiency, required long preparations in terms of synthetic steps that limited their real applicability. As part of our continuing interest in the development of chiral phosphine oxide-catalyzed, Lewis acid-mediated reactions, ${ }^{13}, 19$ we herein report the synthesis of enantiopure $2,2^{\prime}, 5,5^{\prime}$ tetraphenyl-4,4'-bis-(di-(4-methyl)-phenylphosphino)-3,3'bithiophene oxide (TetraPh-Tol-BITIOPO, 4) and its use as organocatalyst, after the resolution of the racemate by semipreparative HPLC, in a few selected stereoselective organic reactions promoted by the activation of a silicon weak Lewis acidic species. 


\section{Result and Discussion}

The synthesis of diphosphine oxide 4 was carried out starting from commercially available 3,3'-bithiophene 1 , having the preformed interanular bond, in order to skip the crucial, hindrance sensitive, coupling reaction of functionalized thiophene units (scheme 1). The bromination of the 3,3'bithiophene in refluxing $\mathrm{CS}_{2}$ afforded the hexabromoderivative 2 in good yields without any further purification need. Unfortunately, the use of $\mathrm{CS}_{2}$ was found to be essential for the success of the reaction since when the reaction was performed both in other solvents, such as $\mathrm{CCl}_{4}, \mathrm{CHCl}_{3}$ and $\mathrm{AcOH}$, or in the absence of solvent, only the 2,2',5,5'-tetrabromothiophene was formed.
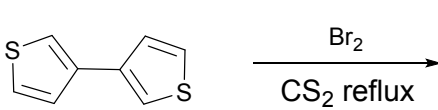<smiles>Brc1sc(Br)c(-c2c(Br)sc(Br)c2Br)c1Br</smiles>

1

2

$88 \%$ yield

$\mathrm{PhB}(\mathrm{OH})_{2}$

$\mathrm{K}_{2} \mathrm{CO}_{3}$ $\mathrm{Pd}\left(\mathrm{PPh}_{3}\right)_{4}$ toluene, reflux, $30 \mathrm{~h}$<smiles>O=[P+]([O-])c1c(-c2ccccc2)sc(-c2ccccc2)c1-c1c(-c2ccccc2)sc(-c2ccccc2)c1[P+](=O)O</smiles>

(rac)-4

TetraPh-Tol-BITIOPO $60 \%$ yield
1) $n$-BuLi, $-50^{\circ} \mathrm{C}$

2) $(\mathrm{p}-\mathrm{Tol})_{2} \mathrm{PCl}$ $-50^{\circ} \mathrm{C}$ to $45^{\circ} \mathrm{C}$

3) $\mathrm{H}_{2} \mathrm{O}_{2} 30 \%$<smiles>Brc1c(-c2ccccc2)sc(-c2ccccc2)c1-c1c(-c2ccccc2)sc(-c2ccccc2)c1Br</smiles>

3

$60 \%$ yield
Scheme 1. Synthesis of TetraPh-Tol-BITIOPO.

The tetraphenylderivative $\mathbf{3}$ was obtained in good yields by means of a regioselective Suzuki coupling reaction mediated by catalytic amounts of Tetrakis(triphenylphosphine)palladium..$^{20}$ Finally, the bis-anion, generated by reaction of $\mathbf{3}$ with $n$-BuLi at $-50{ }^{\circ} \mathrm{C}$, was reacted with 2 equiv. of ditolylphosphinic chloride and the crude product was oxidized in situ with a $30 \%$ hydrogen peroxide solution to give, after chromatographic purification, TetraPh-Tol-BITIOPO 4 in 60\% yield as racemic form.

The separation of the two enantiomers of TetraPh-TolBITIOPO 4 was initially attempted through the formation of diastereomeric adducts with enantiopure chiral acids, following a classical strategy successfully applied to the resolution of the racemates of electron-rich diphosphane oxides. ${ }^{21}$ The reaction can be carried out either with stoichiometric amounts of the enantiopure acid, when the solubility of the two diastereomeric salts is quite different, or with half equiv. of resolving agent in order to induce the preferential crystallization of a single diastereoisomer. Both the strategies were investigated, employing different solvents and resolving agents (see Table 1) but, unfortunately, when the formation: 10fio $\$$ /preeipitate occurred, a racemic mixture was always obtained.

Table 1. Classical resolution attempts

\begin{tabular}{|c|c|c|c|c|}
\hline Solvent ${ }^{[a]}$ & Resolving Agent ${ }^{[a]}$ & Moles & $\begin{array}{l}\text { Precipitate } \\
\text { formation }\end{array}$ & $\begin{array}{l}\text { ee } \\
(\%)\end{array}$ \\
\hline AcOEt & $(-)$-DBTA & 1 & yes & Rac \\
\hline $\mathrm{CHCl}_{3}$ & $(-)$-DBTA & 1 & Yes & Rac \\
\hline THF & $(-)$-DBTA & 1 & No & - \\
\hline $\mathrm{THF} / \mathrm{Et}_{2} \mathrm{O} 1: 1$ & $(-)$-DBTA & 1 & Yes & Rac \\
\hline $\mathrm{THF} / \mathrm{Et}_{2} \mathrm{O} 1: 1$ & $(-)$-DBTA & 0.5 & Yes & Rac \\
\hline $\mathrm{CHCl}_{3}$ & (+)-Naproxen & 0.5 & No & - \\
\hline $\mathrm{CHCl}_{3}$ & $\begin{array}{l}(+)-10- \\
\text { Camphorsulphonic acid }\end{array}$ & 1 & Yes & Rac \\
\hline $\mathrm{CHCl}_{3}$ & $\begin{array}{l}(+) \text {-Binaphthyl } \\
\text { phosphoric acid }\end{array}$ & 1 & yes & rac \\
\hline
\end{tabular}

[a] DBTA = O,O'-Dibenzoyl-L-tartaric acid

The resolution of racemic $\mathbf{4}$ on a multimilligram scale was successfully performed by enantioselective HPLC on chiral stationary phase. Excellent separation of the enantiomers of 4 was achieved by HPLC using the Chiralpak IB column $(250 \mathrm{~mm} \mathrm{x}$ $4.6 \mathrm{~mm} ; 5 \mu \mathrm{m}$ particle size) under normal-phase chlorinated elution mode (i.e. mobile phase: $n$-hexane-dichloromethane-2propanol-diethylamine 70:15:30:0.1 (v/v/v/v)).Typical HPLC UV and $C D$ chromatograms pertinent to the analytical resolution of 4 are shown in Figure 1.

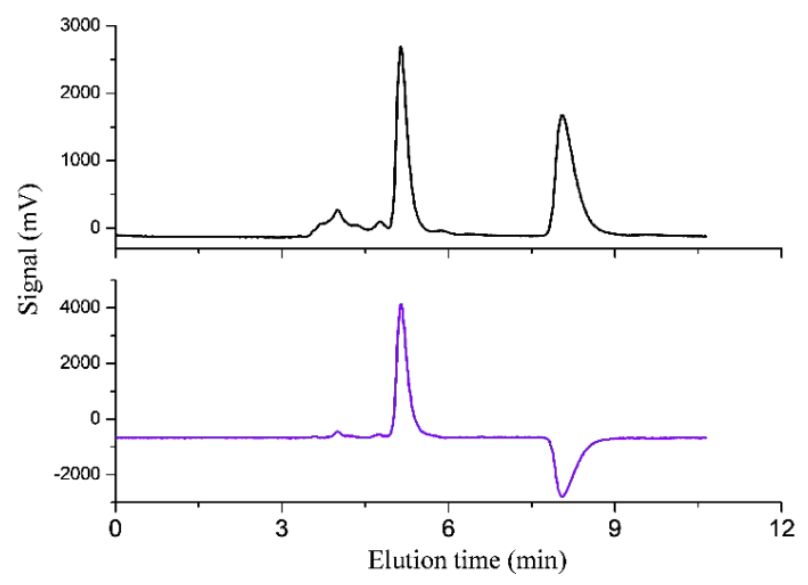

Figure 1: Analytical HPLC resolution of 4. Column, Chiralpak IB $(250 \mathrm{~mm}$ $\times \quad 4.6 \mathrm{~mm}) ;$ mobile phase, $n$-hexane:methylene chloride:2propanol:diethylamine 70:15:30:0.1; flow-rate, $1.0 \mathrm{ml} / \mathrm{min}$; temperature, $40^{\circ} \mathrm{C}$; detection, UV (black) and CD (purple) at $280 \mathrm{~nm}$.

The analytical separation was easily scaled up to a semipreparative scale using a $250 \mathrm{~mm} \times 10 \mathrm{~mm}$ Chiralpak IB 
column. At a flow-rate of $5.0 \mathrm{~mL} / \mathrm{min}$ and a temperature of $40^{\circ}$ C the chromatographic run was completed within 6 min. Therefore, considering that the maximum limit of sample injection onto the $1-\mathrm{cm}$ i.d. Chiralpak IB column was $5 \mathrm{mg}$ (dissolved in $0.5 \mathrm{ml}$ of eluent) and the yields for enantiomeric separations were about $90 \%$, a total of $22.5 \mathrm{mg}$ for each enantiomer per hour could be produced. The enantiomeric excess (ee) value of both fractions collected on a multimilligram level was $>99.0 \%$.

Electronic circular dichroism (ECD) and optical rotation dispersion (ORD) spectra of (4)-antipodes were recorded in order to attribute their absolute configuration (AC). Afterwards, both spectra were compared to the relevant ones simulated by means of Density Function Theory (DFT) calculations (see SI for further details), starting from the (S)-TetraPh-Tol-BITIOPO enantiomer (Figure 2).
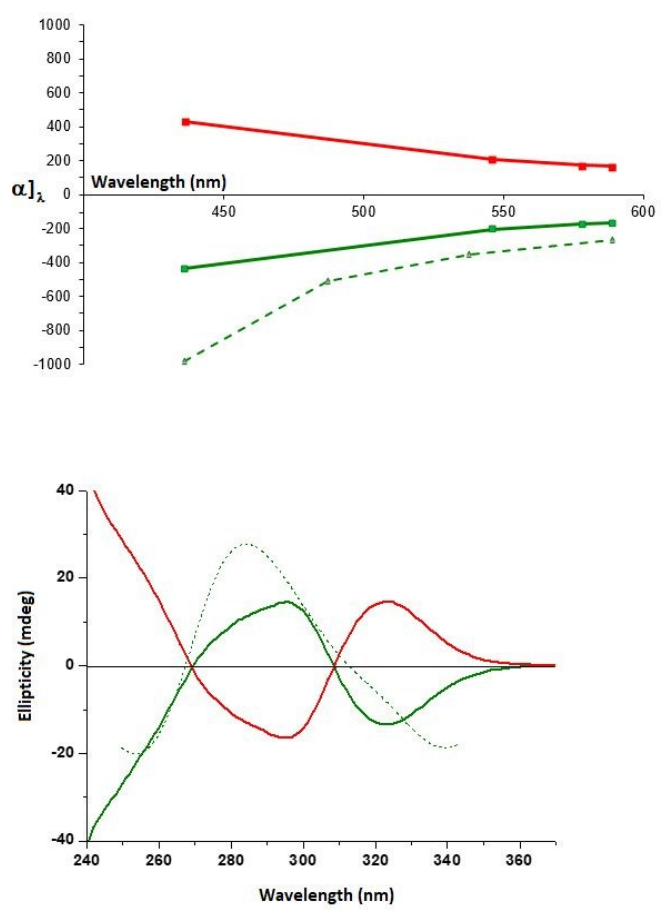

Figure 2: Experimental (full lines) and calculated (dashed lines) ORD and ECD spectra of TetraPh-Tol-BITIOPO enantiomers in chloroform. First eluted (-)-4 is shown as green line; (+)-4 as red line. Dashed traces refer to calculated ORD or ECD spectra of (S)-TetraPh-Tol-BITIOPO enantiomer.

By these analysis, it is possible to attribute the $(S)$ configuration to the first eluted enantiomer (-)-TetraPh-TolBITIOPO.

Optically pure TetraPh-Tol-BITIOPO was then tested as catalyst in a few selected stereoselective Lewis base-catalyzed Lewis acid-mediated reactions (Table 2 ). We initially focused our attention on the stereoselective allylation of aromatic aldehydes: a typical experiment involved the reaction of $1 \mathrm{~mol}$ equiv of aldehyde 5a-g with $1.2 \mathrm{~mol}$ equiv. of allyltrichloro silane in the presence of $0.1 \mathrm{~mol}$ equiv. of catalyst and $3 \mathrm{~mol}$ equiv. of $i-\mathrm{Pr}_{2} \mathrm{NEt}$ in acetonitrile for $40 \mathrm{~h}$ at $0^{\circ} \mathrm{C} .{ }^{12 b}$ Isolated yields and enantiomeric excesses of alcohols 6a-g were determined by HPLC on a chiral stationary phase and the absolute configuration was assigned by comparison with literature data (see supporting information). Preliminary experiments with benzaldehyde (5a) undeostandaedcoonditions afforded homoallyl alcohol (6a) in $87 \%$ yield and $70 \%$ ee (entry $1)$. These result are comparable with those reported in literature for analogous bitiophene-based catalyst. ${ }^{12 b}$ However, in order to further improve the TetraPh-Tol-BITIOPO solubility, the use of dichloromethane was also investigated. In this case, the desired product 5a was obtained with $94 \%$ ee, even if yield decrease to $50 \%$ (entry 2). Since 4 exhibited improved chemical efficiency when operating in $\mathrm{CH}_{2} \mathrm{Cl}_{2}$, we decided to extend the substrate scope by performing in $\mathrm{CH}_{2} \mathrm{Cl}_{2}$ the reaction with diversely substituted aromatic aldehydes, bearing electron donating and electron withdrawing substituents on the aromatic ring (entries 3-5). In all cases, products were obtained in modest yields but with high enantioselectivities, up to $96 \%$ ee, demonstrating that the catalyst is able to effectively control the stereoselection of the process. More interesting, catalyst 4 showed high chemical efficiency in the allylation of cinnamaldehyde $\mathbf{5 e}$ allowing to the formation of product $\mathbf{6 e}$ in complete conversion and with $70 \%$ ee (entry 6 ).

(-)-TetraPh-Tol-BITIOPO confirmed its activity also at low temperatures, since the reaction of $\mathbf{5 e}$ performed at $-20^{\circ} \mathrm{C}$ afforded the product $6 \mathrm{e}$ in $96 \%$ yield and $69 \%$ ee (entry 7 ). The 4-catalyzed allylation of heteroaromatic aldehydes, such as 2thiophenyl carboxaldehyde $\mathbf{5 f}$, was also investigated and product $\mathbf{6 f}$ was obtained in $60 \%$ yield and $76 \%$ ee (entry 8 ).

Encouraged by these results, we extended the use of catalyst 4 to other Lewis base-catalyzed Lewis acid mediated reactions such as the direct aldol reaction between aromatic aldehydes with both ketones and thioesters (Scheme 2a and b) as well as the direct double aldol reaction between aryl methyl ketones with aromatic aldehydes in the presence of tetrachlorosilane (Scheme $2 \mathrm{c}$ ). The reaction between cyclohexanone and benzaldehyde was investigated in the presence of stoichiometric amounts of $\mathrm{SiCl}_{4}$ and a catalytic amount of enantiomerically pure (-)-TetraPh-Tol-BITIOPO at -25 ${ }^{\circ} \mathrm{C}$ for 36 hours. ${ }^{19 b} \beta$-Hydroxy-etone 8a was obtained in $70 \%$ yield very high anti selectivity (95:5 anti:syn ratio) and in $51 \%$ enantiomeric excess for the $(1 ' S, 2 R)$-8a-anti enantiomer.

The performances of tetraPh-Tol-BITIOPO were also investigated in the organocatalytic stereoselective direct aldol reaction of trifluoroethyl thioester $\mathbf{9}$ performed according to literature procedure. ${ }^{13}$ The corresponding $\beta$-hydroxy thioester 10a was obtained in $74 \%$ yield with 76:24 syn:anti ratio, although a decrement in terms of enantioselectivity was observed. However, these results are remarkable considering that TetraPh-Tol-BITIOPO showed an increased reactivity compared to the use of BINAPO (which is not able to effectively promote this type of transformation).

Finally, the direct double aldol reaction between acetophenone (11) and benzaldehyde mediated by the presence of $\mathrm{SiCl}_{4}$ was also explored. Double aldol product was isolated as diacetate form in good yield and 86:14 ratio between the chiral isomer 12-chiro and the achiral 12-meso stereoisomers, with $60 \%$ ee for the chiral one (it must be noted that 12-meso is an achiral molecule that may exist in two diastereoisomers, however in this case only one form was observed by ${ }^{1} \mathrm{H}-\mathrm{NMR}$.

These results represent only the starting point for further investigation to expand the application of this new class of phosphine oxides in other Lewis base-catalyzed Lewis acidmediated transformations. 
Table 2. Substrate scope of the enantioselective addition of allyltrichorosilane to aldehydes

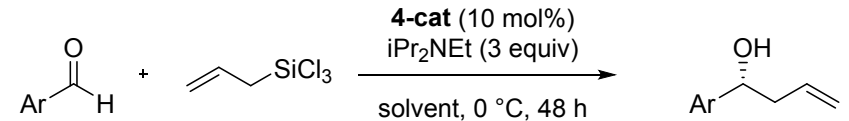

5a-g

6a-g

\begin{tabular}{|c|c|c|c|c|c|c|c|}
\hline Entry & Aldehyde & $\operatorname{Ar}$ & Catalyst & Solvent & Product & Yield (\%) & ee $(\%)^{[a]}$ \\
\hline 1 & $5 a$ & $\mathrm{C}_{6} \mathrm{H}_{5}$ & (-)-(S)-TetraPh-Tol-BITIOPO & $\mathrm{CH}_{3} \mathrm{CN}$ & $6 a$ & 87 & $70(S)$ \\
\hline 2 & $5 a$ & $\mathrm{C}_{6} \mathrm{H}_{5}$ & $(+)$-(R)-TetraPh-Tol-BITIOPO & $\mathrm{CH}_{2} \mathrm{Cl}_{2}$ & $6 a$ & 50 & $94(R)$ \\
\hline 3 & $5 b$ & $4-\mathrm{OCH}_{3}-\mathrm{C}_{6} \mathrm{H}_{4}$ & $(+)-(R)$-TetraPh-Tol-BITIOPO & $\mathrm{CH}_{3} \mathrm{CN}: \mathrm{CH}_{2} \mathrm{Cl}_{2}(1: 1)$ & $6 b$ & 49 & $94(R)$ \\
\hline 5 & $5 d$ & $4-\mathrm{NO}_{2}-\mathrm{C}_{6} \mathrm{H}_{4}$ & $(-)-(S)$-TetraPh-Tol-BITIOPO & $\mathrm{CH}_{3} \mathrm{CN}$ & $6 d$ & 50 & $90(S)$ \\
\hline 6 & $5 e$ & $\mathrm{Ph}-\mathrm{CH}=\mathrm{CH}-$ & (-)-(S)-TetraPh-Tol-BITIOPO & $\mathrm{CH}_{3} \mathrm{CN}$ & $6 e$ & 98 & $70(S)$ \\
\hline $7^{[\mathrm{b}]}$ & $5 e$ & $\mathrm{Ph}-\mathrm{CH}=\mathrm{CH}-$ & $(+)-(R)$-TetraPh-Tol-BITIOPO & $\mathrm{CH}_{3} \mathrm{CN}$ & $6 e$ & 96 & $69(\mathrm{R})$ \\
\hline 8 & $5 f$ & 2-Thiophenyl & (-)-(S)-TetraPh-Tol-BITIOPO & $\mathrm{CH}_{2} \mathrm{Cl}_{2}$ & $6 f$ & 60 & $76(S)$ \\
\hline 9 & $5 g$ & $\mathrm{Ph}-\mathrm{CH}_{2} \mathrm{CH}_{2}$ & $(+)-(R)$-TetraPh-Tol-BITIOPO & $\mathrm{CH}_{2} \mathrm{Cl}_{2}$ & $6 \mathrm{~g}$ & 43 & rac \\
\hline
\end{tabular}

${ }^{a}$ determined using HPLC on a chiral stationary phase. ${ }^{b}$ stereogenic center configuration was assigned based on comparison with literature data. ${ }^{c}$ reaction conducted at $-20^{\circ} \mathrm{C}$.

a) Direct aldol addition between benzaldehyde and cicloexanone

(-)-4 (10 mol\%)<smiles>O=C1CCCCC1</smiles>

$5 a$

7

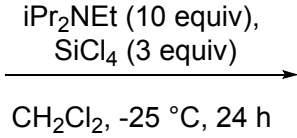<smiles>O=C1CCCCC1[C@H](O)c1ccccc1</smiles>

8a-anti

yield $=70 \%$ anti:syn $95: 5,51 \%$ ee $(a n t i)$

b) Direct aldol addition of activated thioester to benzaldehyde

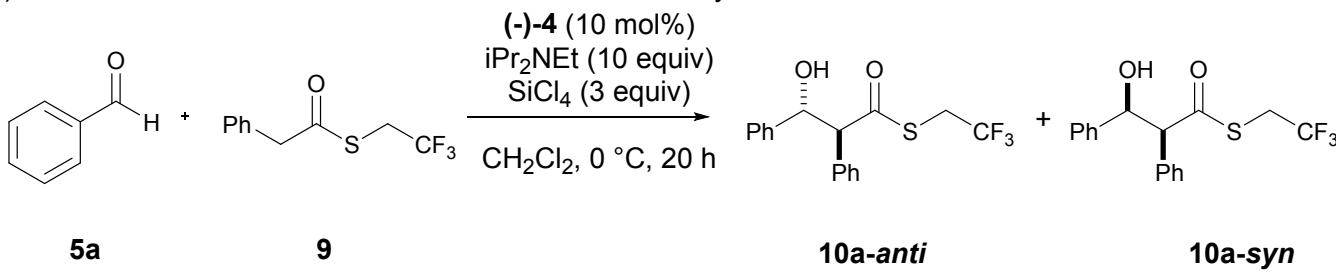

yield $=74 \%$, anti:syn $24: 76,60 \%$ ee (anti), $36 \%$ ee (syn)

c) Direct double aldol addition between benzaldehyde and acetophenone

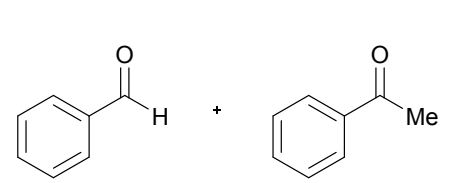

$5 a$

11
(-)-4 (10 mol\%), iPr ${ }_{2}$ NEt (5 equiv),

$\mathrm{SiCl}_{4}(3$ equiv)
$\mathrm{CH}_{2} \mathrm{Cl}_{2},-40^{\circ} \mathrm{C}, 20 \mathrm{~h}$
2) $\mathrm{Ac}_{2} \mathrm{O} / \mathrm{Py}$

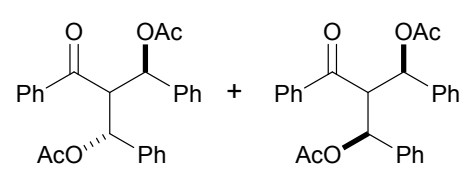

12-chiro 12-meso

yield $=64 \%$, chiro:meso $86: 14,60 \%$ ee (chiro)

Scheme 2. Direct (Double) aldol reaction of benzaldehyde with activated nucleophiles.

A comparison in terms of chemical and stereochemical efficiency between the new synthetized catalyst TetraPh-Tol-
BITIOPO (4) and the previously reported TetraMe-BITIOPO $(13)^{12 b}$ shows that both two compounds are able to promote the 
allylation of aldehydes with good yields and high levels of stereoselectivities. However, a lower level of enantioselection was observed when the direct aldol reaction between benzaldehyde and cyclohexanone was performed in the presence of catalyst 4 . Surprisingly, the two catalysts, featuring the same 3,3'-bithiophene chiral scaffold afforded, in all the investigated reactions, enantiomers with opposite configuration while retaining, in the case of direct aldol reaction, the same diastereoselectivity. ${ }^{19 b}$

In order to elucidate the origin of this behavior, the direct aldol reaction promoted by both TetraMe-BITIOPO (13) and
TetraPh-Tol-BITIOPO was studied by semiempirical calculations (scheme 3). Initially, a conformational analysis owithokMonte carlo technique was performed using the OPLS_2005 force field ${ }^{22}$ with Macromodel Schrodinger suite package ${ }^{23}$ on a model of the TSs, in order to obtain the best geometrical arrangement for the different substituents. Then, the two structures leading to the formation of the two experimentally observed anti products, were fully optimized to the relative genuine TSs with AM1 methods (both with only one imaginary frequency). ${ }^{25}$

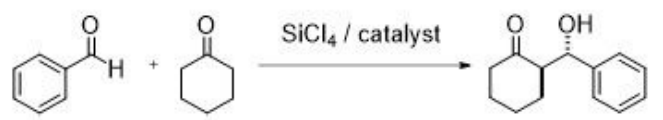

5 a 7

(S)-TetraMe-BITIOPO

$70 \%$ yield, anti:syn $93: 3,81 \%$ ee $\left(2 \mathrm{~S}, 1^{\prime} \mathrm{R}\right)-8 \mathrm{a}$

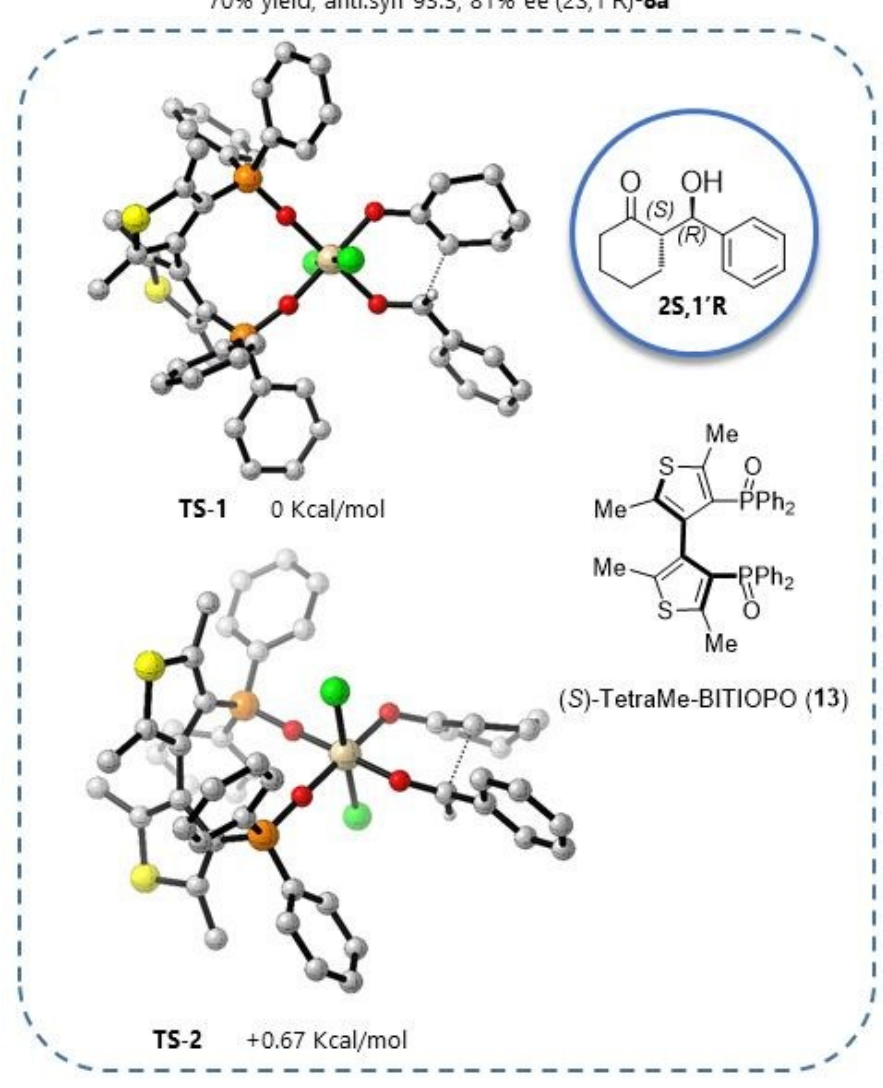

8a-anti (major product)

(S) -Tetra-Ph-Tol-BITIOPO $70 \%$ yield, anti:syn $95: 5,51 \%$ ee $\left(2 \mathrm{R}, 1^{\prime} \mathrm{S}\right)-8 \mathrm{a}$

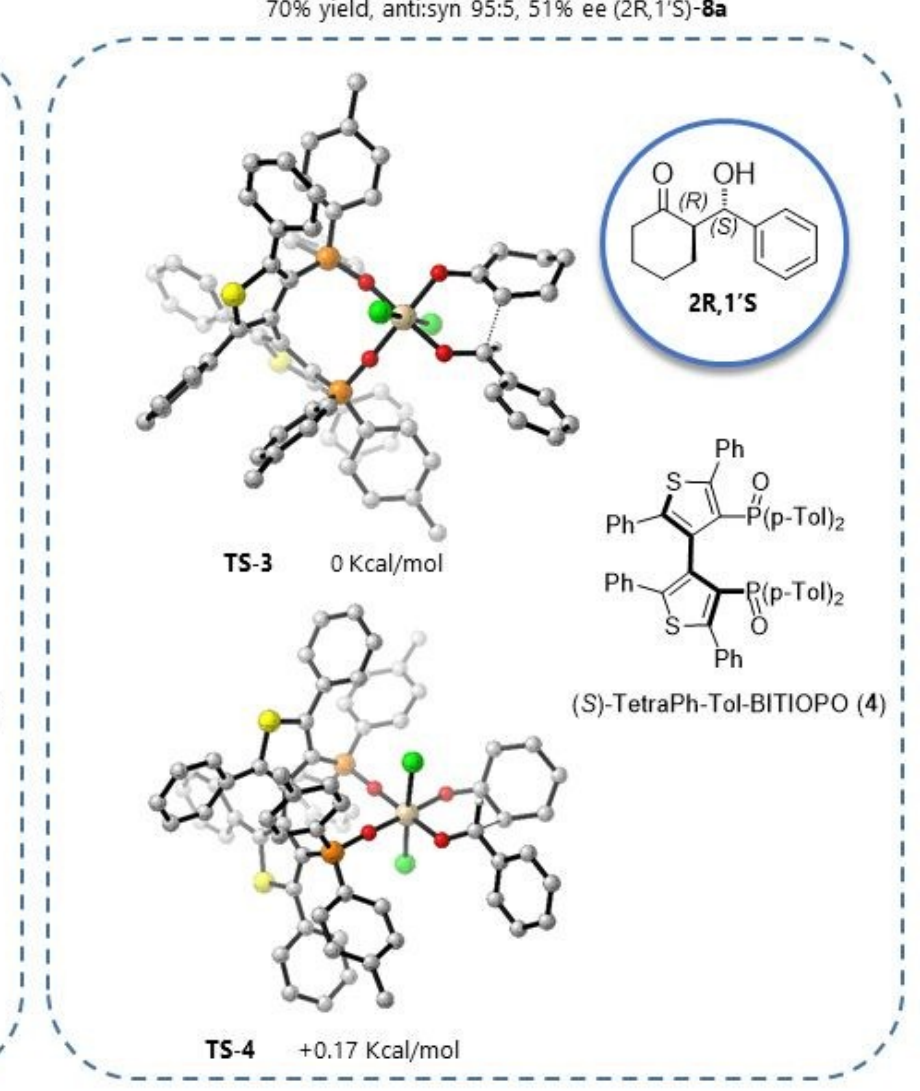

Scheme 3. $\Delta \Delta \mathrm{G}$ in $\mathrm{kcal} / \mathrm{mol}$ at the B3LYP/6-31G $(\mathrm{p}, \mathrm{d}$ ) level of theory of TSs related to the aldol addition reaction mediated by SiCl 4 and promoted by BITIOPOs catalysts (hydrogen were omitted for clarity, cream = silicon, yellow = sulfur, green = chlorine, red = oxygen, orange = phosphorous, grey = carbon).

The calculations, performed using (S)-TetraMe-BITIOPO (13) as catalyst, showed that TS-1, responsible of the formation of the experimentally observed anti- $\left(2 \mathrm{~S}, 1^{\prime} \mathrm{R}\right)$-diastereoisomer, was more stable by $0.67 \mathrm{kcal} / \mathrm{mol}$ than TS-2. The same calculations using (S)-TetraPh-tol-BITIOPO (4) showed instead an opposite trend: TS-3, which leads to the formation of anti$\left(2 \mathrm{R}, 1^{\prime} \mathrm{S}\right)-(8 \mathrm{a})$-diastereoisomer is more stable of $0.17 \mathrm{kcal} / \mathrm{mol}$ than TS-4. The energy differences between the TSs determined by computational studies are in good agreement with the experimentally observed lower enantioselectivity obtained with catalyst (S)-4 compared to the (S)-TetraMe-BITIOPO derivative (13).

This unexpected behavior could be explained with the presence in catalyst 4 of a $\pi-\pi$ interaction between a phenyl group of the 3,3'-bithienyl scaffold with the tolyl group connected to the phosphorous atom. Such interaction cause a different local atom rearrangement in the chiral pocket generated by the hypervalent silicon species $\mathrm{SiCl}_{4}$-catalyst(4), compared to those generated when $(S)$-TetraMe-BITIOPO was employed. 


\section{Conclusion}

A new atropisomeric diphosphine oxide based on the 3,3'bithiophene scaffold was synthesized and resolved into antipodes through semipreparative chiral HPLC. Their absolute configuration was assigned on the basis of the comparison between experimental and DFT calculated ECD and ORD spectra. The enantiomers were tested as organocatalysts to promote the enantioselective allylation of aldehydes, in up to $96 \%$ e.e., and aldol type reactions, with lower stereoselectivities.

Although the stereocontrol induced by the new atropisomeric catalyst was not completely satisfactory, a simple replacement of a methyl group with a phenyl ring on the 3,3'atropisomeric bithiophene scaffold produces a strong modification on the stereochemical outcome of the reactions.

Since further studies are clearly needed to investigate this new class of chiral catalysts, the present work opens the pathway towards the design of new, highly tunable biheterocyclic phosphine derivatives, to be employed as chiral promoters in stereoselective transformations.

\section{Experimental}

General: All reactions were carried out in oven-dried glassware with magnetic stirring under nitrogen unless otherwise stated. Dry solvents were purchased and stored under nitrogen over molecular sieves (bottles with crown caps). Reactions were monitored by analytical TLC using silica gel 60 F254 precoated glass plates $(0.25$ $\mathrm{mm}$ thickness) and visualized by using UV light. Flash chromatography was carried out on silica gel (230-400 mesh). ${ }^{1} \mathrm{H}$ NMR spectra were recorded with a Bruker Fourier or Bruker Advanced spectrometer operating at 300 or $500 \mathrm{MHz} .{ }^{1} \mathrm{H}$ chemical shifts are reported in ppm $(\delta)$ with the solvent as reference relative to tetramethylsilane (TMS) employed as internal standard $\left(\mathrm{CDCl}_{3}: \delta\right.$ $=7.26 \mathrm{ppm}) \cdot{ }^{13} \mathrm{C}$ NMR spectra were recorded with the same spectrometer at $125 \mathrm{MHz}$ with complete proton decoupling. ${ }^{13} \mathrm{C}$ chemical shifts are reported in ppm $(\delta)$ relative to TMS with the respective solvent resonance as internal standard $\left(\mathrm{CDCl}_{3}: \delta=77.0\right.$ $\mathrm{ppm}) .{ }^{31} \mathrm{P}$ spectra were recorded at $121.4 \mathrm{MHz}$ and were referenced to phosphoric acid $\left(\mathrm{H}_{3} \mathrm{PO}_{4}\right)$ at $0.0 \mathrm{ppm}$. Enantiomeric excesses were determined by HPLC with Agilent 1100 and 1200 series HPLC systems. CD spectra were recorded by using a Jasco Model J-700 spectropolarimeter. DFT calculations where performed by using the Gaussian 09 package. Hexabromo-3,3'-bithiophene (2) and 4,4'dibromo-2,2',5,5'-tetraphenyl-3,'-bithiophene (3) were prepared according to the procedures reported in ref. 25 .

\section{2,2',5,5'-Tetraphenyl-4,4'-bis-(di-(4-methyl)-phenylphosphino)-} 3,3'-bithiophene oxide (TetraPh-Tol-BITIOPO, 4). 1.6M n-BuLi solution ( $6 \mathrm{~mL}$ ) was added dropwise under stirring into a solution of $3(2.5 \mathrm{~g}, 3.97 \mathrm{mmol})$ in dry THF $(20 \mathrm{~mL})$ under Argon atmosphere at $-50{ }^{\circ} \mathrm{C}$. After $45 \mathrm{~min}$ the temperature was allowed to warm up to $40{ }^{\circ} \mathrm{C}$ and ditolylphosphinic acid was added dropwise (2.0 g 8.1 $\mathrm{mmol})$. The reaction mixture was refluxed for $8 \mathrm{~h}$ and the solvent evaporated under reduced pressure. The residue was dilute with
$\mathrm{CH}_{2} \mathrm{Cl}_{2}\left(20 \mathrm{~mL}\right.$ ) and a $30 \% \mathrm{H}_{2} \mathrm{O}_{2}$ solution (10.4 mL 2.4. mmol) was

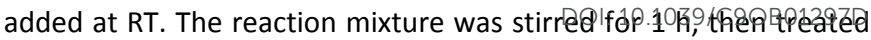
with a $1 \mathrm{~N} \mathrm{HCl}$ solution $(30 \mathrm{~mL})$. The organic layer was washed with a saturated $\mathrm{NaHCO}_{3}$ solution $(30 \mathrm{~mL}$ ); the aqueous phase was extracted with $\mathrm{CH}_{2} \mathrm{Cl}_{2}(3 \times 30 \mathrm{~mL})$ and the combined organic layer was dried over anhydrous $\mathrm{Na}_{2} \mathrm{SO}_{4}$ and evaporated under reduced pressure. The residue was purified by flash column chromatography on silica gel with a $\mathrm{CH}_{2} \mathrm{Cl}_{2}$ /ethyl acetate/ $\mathrm{Et}_{3} \mathrm{~N}$ mixture (7:3:0.1). The last fractions eluted was combined and evaporated to dryness to give 4 as a white solid (60\% yield); m.p. $134{ }^{\circ} \mathrm{C}$ (uncorrected). ${ }^{1} \mathrm{H}$ NMR $\left(300 \mathrm{MHz}, \mathrm{CDCl}_{3}\right): \delta=7.30-6.90(\mathrm{~m}, 16 \mathrm{H}), 6.81(\mathrm{dd}, J=2.4 \mathrm{~Hz}, 2 \mathrm{H})$, $6.71(\mathrm{dd}, J=2.4 \mathrm{~Hz} ., 2 \mathrm{H}), 2.22(\mathrm{~s}, 3 \mathrm{H}), 2.16(\mathrm{~s}, 3 \mathrm{H}) .{ }^{13} \mathrm{C} \mathrm{NMR}(75 \mathrm{MHz}$, $\left.\mathrm{CDCl}_{3}\right): \delta=151.15,150.97,142.14,141.97,140.29,135.67,135.50$, $134.09,133.40,132.31,132.17,132.04,131.90,131.37,131.23$, $130.67,129.92,129.83,129.36,128.98,128.65,128.54,128.24$, $128.05,127.86,127.47,127.29,126.95,21.48,21.41$. ${ }^{31}$ P NMR (121.4 $\left.\mathrm{MHz}, \mathrm{CDCl}_{3}\right): \delta=21.82 . \mathrm{MS}(\mathrm{EI}) 926(\mathrm{M}+)$.

General procedure for the enantioselective allylation of aldehydes 5a-g with allyltrichlorosilane: Allyltrichlorosilane $(40,49 \mathrm{mg}, 0.214$ $\mathrm{mmol}, 1.2$ equiv) was added dropwise to a mixture of TetraPh-TolBITIOPO (4) (0.017 mg, $0.018 \mathrm{mmol}, 0.1 \mathrm{~mol} \%)$, freshly distilled aldehyde (5) (0.178 mmol, 1 equiv), and diisopropylethylamine ( $0.093 \mathrm{~mL}, 0.534 \mathrm{mmol}, 3$ equiv) dissolved in the desired solvent ( 1.2 $\mathrm{mL}, 0.15 \mathrm{M}$ ) under nitrogen at $0{ }^{\circ} \mathrm{C}$. The reaction mixture was stirred at this temperature for $48 \mathrm{~h}$, then it was quenched with a saturated $\mathrm{NaHCO}_{3}$ aqueous solution ( $1 \mathrm{~mL}$ ). The mixture was allowed to warm up to room temperature, then the layers were separated and the aqueous layer was extracted with ethyl acetate $(2 \times 5 \mathrm{~mL})$. The combined organic layer was washed with aqueous sodium chloride, dried over anhydrous $\mathrm{Na}_{2} \mathrm{SO}_{4}$ and evaporated under reduced pressure. The residue was purified by flash column chromatography on silica gel with a $n$-hexane/ethyl acetate mixture (9:1). The yields and enantioselectivities are given in Table 2. Analytical and spectral data are available in the Supporting Information.

General procedure of enantioselective direct aldol-type reaction between ketones or thioesters and aldehydes: To a stirred solution of enantiopure TetraPh-Tol-BITIOPO $4(0.017 \mathrm{mg}, 0.018 \mathrm{mmol}, 0.1$ mol\%), in dichloromethane $(1.2 \mathrm{~mL})$, diisopropylethylamine $(0.310$ $\mathrm{mL}, 1.78 \mathrm{mmol}, 10$ equiv) and cyclohexanone $(0.035 \mathrm{~g}, 0.356 \mathrm{mmol}, 2$ equiv) or thioester 9 (0.099, $0.356 \mathrm{mmol}, 2$ equiv) were added. The mixture was then cooled at $0{ }^{\circ} \mathrm{C}$ and freshly distilled tetrachlorosilane ( $0.031 \mathrm{~mL}, 0.267 \mathrm{mmol}, 1.5$ equiv) was added dropwise via syringe. After $15 \mathrm{~min}$, freshly distilled aldehyde $(0.018 \mathrm{~mL}, 0.178 \mathrm{mmol}, 1$ equiv) was added. The mixture was stirred for $5 / 12$ hours ( $5 \mathrm{~h}$ for thioesters, $12 \mathrm{~h}$ for ketones), then the same amount of tetrachlorosilane (1.5 equiv) was added. After further 12/15 hours (15 $\mathrm{h}$ for thioesters, $12 \mathrm{~h}$ for ketones), the reaction was quenched by the addition of a saturated $\mathrm{NaHCO}_{3}$ aqueous solution $(3 \mathrm{~mL})$. The mixture was allowed to warm up to room temperature and stirred for $30 \mathrm{~min}$, then water $(2.5 \mathrm{~mL})$ and ethyl acetate $(8 \mathrm{~mL})$ were added. The two-layers mixture was separated and the aqueous layer was extracted with ethyl acetate $(8 \mathrm{~mL})$. The combined organic layers were washed with $10 \% \mathrm{HCl}(10 \mathrm{~mL})$, sat $\mathrm{NaHCO}_{3}(10 \mathrm{~mL})$ and brine $(10 \mathrm{~mL})$, dried over $\mathrm{Na}_{2} \mathrm{SO}_{4}$, filtered and concentrated under vacuum at room temperature. The crude product was purified by column chromatography with $n$-hexane/ethyl acetate 9:1 mixture as eluent 
to afford the pure aldol adducts (see scheme 2). The syn/anti ratio was evaluated by ${ }^{1} \mathrm{H}$ NMR spectroscopy of the crude mixture; the enantiomeric excesses were determined by HPLC. Catalyst $\mathbf{4}$ was quantitatively recovered by further elution with $10 \% \mathrm{MeOH}$ in $\mathrm{CH}_{2} \mathrm{Cl}_{2}$ without any loss of optical purity (for example: recovered (+)-4 catalyst $[\alpha]_{25}^{\mathrm{D}}=+138.8, \mathrm{c}=0.78$ in $\mathrm{CHCl}_{3}$ ).

General procedure of enantioselective direct double aldol-type reaction: To a stirred solution of enantiopure TetraPh-Tol-BITIOPO 4 (0.017 mg, $0.018 \mathrm{mmol}, 0.1 \mathrm{~mol} \%)$ in dichloromethane $(1.2 \mathrm{~mL})$, diisopropylethylamine $(0.155 \mathrm{~mL}, 0.89 \mathrm{mmol}, 5$ equiv) and acetophenone $(0.021 \mathrm{~g}, 0.178 \mathrm{mmol}, 1$ equiv) were added. The mixture was then cooled at $-40{ }^{\circ} \mathrm{C}$ and freshly distilled tetrachlorosilane $(0.081 \mathrm{~mL}, 0.712 \mathrm{mmol}, 4$ equiv) was added dropwise via syringe. After $15 \mathrm{~min}$, freshly distilled aldehyde $(0.044$ $\mathrm{mL}, 0.391 \mathrm{mmol}, 2.2$ equiv) was added. The mixture was stirred for $20 \mathrm{~h}$. After this time, the reaction was quenched by the addition of a saturated $\mathrm{NH}_{4} \mathrm{Cl}$ aqueous solution $(2 \mathrm{~mL}$ ). The mixture was allowed to warm to room temperature and stirred for $30 \mathrm{~min}$, then $\mathrm{CH}_{2} \mathrm{Cl}_{2}(10$ $\mathrm{mL}$ ) was added. The two-layer mixture was separated and the aqueous layer was extracted with $\mathrm{CH}_{2} \mathrm{Cl}_{2}(15 \mathrm{~mL})$. The combined organic layers were dried over $\mathrm{Na}_{2} \mathrm{SO}_{4}$, filtered, and concentrated under vacuum at room temperature to give the crude 1,3-diols, as confirmed by ${ }^{1} \mathrm{H}-\mathrm{NMR}$. The crude products were then treated with acetic anhydride ( $0.185 \mathrm{~mL}, 1.95 \mathrm{mmol}, 11$ equiv) in $2 \mathrm{~mL}$ of pyridine at RT. After stirring for $20 \mathrm{~h}$, the mixture was quenched with $\mathrm{H}_{2} \mathrm{O}$ (5 $\mathrm{mL})$ and extracted with $\mathrm{CH}_{2} \mathrm{Cl}_{2}(2 \times 8 \mathrm{~mL})$. The combined organic layers were dried over $\mathrm{Na}_{2} \mathrm{SO}_{4}$, filtered, and concentrated under vacuum at RT. The crude product was purified by column chromatography with $n$-hexane/ethyl acetate 9:1 mixture as eluent to afford the pure aldol adducts (see scheme 2).

\section{Conflicts of interest}

There are no conflicts to declare.

\section{Acknowledgements}

This work was conducted with financial support from Sapienza University of Rome, Italy (DR n 3210/16 of 16/12/2016 and DR n. 2936/17 of 20/11/2017) and from Università degli Studi di Milano, Italy (Piano Sostegno alla Ricerca-PSR2018 grant to SG).

\section{Notes and references}

1 S. E. Denmark, G. L. Beutner, Angew Chem Int Ed. 2008, 47, 1560.

2 a) R. J. P. Corriu, J. C. Young, D. A. Armitage, R. J. P. Corriu, T. C. Kendrick, B. Parbhoo, T. D. Tilley, J. W. White, J. C. Young, in The Silicon-Heteroatom Bond (1991), John Wiley \& Sons, Inc, pp. 1-48; b) J. Wagler, U. Böhme, E. Kroke, HigherCoordinated Molecular Silicon Compounds 2013, 155, 29 Springer Ed.; c) S. E. Denmark, G. L. Beutner, Principles, Definitions, Terminology, and Orbital Analysis of Lewis BaseLewis Acid Interactions Leading to Catalysis, in Lewis Base Catalysis in Organic Synthesis 2016, 31, Wiley-VCH Verlag $\mathrm{GmbH} \&$ Co. KGaA.
3 S. Rossi, S. E. Denmark, Lewis Base-Catalyzed Lewis AcidMediated Reactions $\left(n \rightarrow \sigma^{*}\right)$ in Lewis Bases Catablsis 9 in Organic Synthesis, Wiley-VCH Verlag GmbH \& Co. KGaA, 2016, 1039.

4 S. Kobayashi, K. Nishio, Tetrahedron Letters 1993, 34, 3453.

5 a) M. Benaglia, S. Guizzetti, L. Pignataro, Coord. Chem. Rev. 2008, 252, 492; b) M. Benaglia, S. Guizzetti, S. Rossi, SilicateMediated Stereoselective Reactions Catalyzed by Chiral Lewis Bases in Catalytic Methods in Asymmetric Synthesis, John Wiley \& Sons, Inc., 2011, 579; c) S. Rossi, M. Benaglia, A. Genoni, Tetrahedron 2014, 70, 2065.

6 [6] P. Kočovský, A. V. Malkov, Lewis Bases as Catalysts in the Reduction of Imines and Ketones with Silanes $\left(n \rightarrow \sigma^{*}\right)$ in Lewis Base Catalysis in Organic Synthesis, Wiley-VCH Verlag GmbH \& Co. KGaA, 2016, 1077.

7 a) S. Jones, C. J. Warner, Org Biomol Chem 2012, 10, 2189; b) S. Rossi, M. Benaglia, E. Massolo, L. Raimondi, Cat Sci Technol 2014, 4, 2708; c) A. V. Malkov, P. Kočovský, Lewis BaseCatalyzed Reactions of SiX3-Based Reagents with $C=O, C=N$ $\left(n \rightarrow \sigma^{*}\right)$ in Lewis Base Catalysis in Organic Synthesis, WileyVCH Verlag GmbH \& Co. KGaA, 2016, 1011.

8 For a few selected examples see: a) S. E. Denmark, D. M. Coe, N. E. Pratt, B. D. Griedel, J. Org. Chem. 1994, 59, 6161; b) S. E. Denmark, K. T. Wong, R. A. Stavenger, J Am Chem Soc 1997, 119, 2333; c) S. E. Denmark, J. Fu, J Am Chem Soc 2000, 122, 12021 ; d) S. E. Denmark, S. K. Ghosh, Angew Chem Int Ed 2001, 40, 4759; e) S. E. Denmark, T. Wynn, J Am Chem Soc 2001, 123, 6199; f) S. E. Denmark, T. Wynn, G. L. Beutner, J Am Chem Soc 2002, 124, 13405; g) S. E. Denmark, G. L. Beutner, J Am Chem Soc 2003, 125, 7800; h) S. E. Denmark, Y. Fan, J Am Chem Soc 2003, 125, 7825; i) S. E. Denmark, J. Fu, J Am Chem Soc 2003, 125, 2208; j) S. E. Denmark, G. L. Beutner, T. Wynn, M. D. Eastgate, J Am Chem Soc 2005, 127, 3774; k) S. E. Denmark, J. R. Heemstra, G. L. Beutner, Angew Chem Int Ed 2005, 44, 4682; I) S. E. Denmark, J. R. Heemstra, Jr., J Am Chem Soc 2006, 128, 1038; m) S. E. Denmark, P. A. Barsanti, G. L. Beutner, T. W. Wilson, Adv Synth Catal 2007, 349, 567; n) S. E. Denmark, W. J. Chung, Angew Chem Int Ed 2008, 47, 1890; o) S. E. Denmark, B. M. Eklov, P. J. Yao, M. D. Eastgate, J Am Chem Soc 2009, 131, 11770; p) S. E. Denmark, T. W. Wilson, Nat Chem 2010, 2, 937; q) S. E. Denmark, T. W. Wilson, Angew Chem Int Ed 2012, 51, 3236; r) S. E. Denmark, T. W. Wilson, Angew Chem Int Ed 2012, 51, 9980.

9 a) M. Benaglia, S. Rossi, Org Biomol Chem 2010, 8, 3824; b) M. Sugiura, N. Sato, Y. Sonoda, S. Kotani, M. Nakajima, Chemistry, an Asian Journal 2010, 5, 478; c) Y. Shimoda, S. Kotani, M. Sugiura, M. Nakajima, Chem. Eur. J 2011, 17, 7992; d) P. Zhang, Z. Han, Z. Wang, K. Ding, Angew Chem Int Ed 2013, 52, 11054; e) Y. Shimoda, T. Kubo, M. Sugiura, S. Kotani, M. Nakajima, Angew Chem Int Ed 2013, 52, 3461; f) S. Kotani, M. Sugiura, M. Nakajima, Chemical Record 2013, 13, 362; g) S. Kotani, S. Miyazaki, K. Kawahara, Y. Shimoda, M. Sugiura, M. Nakajima, Chem Pharm Bull 2016, 64, 189; h) S. Kotani, K. Kai, M. Sugiura, M. Nakajima, Org Lett 2017, 19, 3672; i) S. Kotani, Y. Yoshiwara, M. Ogasawara, M. Sugiura, M. Nakajima, Angew Chem Int Ed 2018, 57, 15877.

10 a) G. L. Beutner, S. E. Denmark, Angew Chem Int Ed 2013, 52, 9086; b) S. E. Denmark, R. A. Stavenger, Acc Chem Res 2000, 33, 432.

11 S. Kotani, S. Aoki, M. Sugiura, M. Ogasawara, M. Nakajima, Org Lett 2014, 16, 4802.

12 a) T. Benincori, E. Cesarotti, O. Piccolo, F. Sannicolò, J Org Chem 2000, 65, 2043; b) V. Simonini, M. Benaglia, T. Benincori, Adv Synth Catal 2008, 350, 561.

13 S. Rossi, M. Benaglia, F. Cozzi, A. Genoni, T. Benincori, Adv Synth Catal 2011, 353, 848.

14 M. Ogasawara, S. Kotani, H. Nakajima, H. Furusho, M. 
Miyasaka, Y. Shimoda, W. Y. Wu, M. Sugiura, T. Takahashi, M. Nakajima, Angew Chem Int Ed 2013, 13798.

15 X. Pu, X. Qi, J. M. Ready, J Am Chem Soc 2009, 131, 10364.

16 Y. Ohmaru, N. Sato, M. Mizutani, S. Kotani, M. Sugiura, M. Nakajima, Org Biomol Chem 2012, 10, 4562.

17 a) Ö. Dogan, A. Bulut, M. A. Tecimer, Tetrahedron: Asymmetry 2015, 26, 966; b) Ö. Dogan, D. Tan, Tetrahedron: Asymmetry 2015, 26, 1348.

18 a) N. Sevrain, J.-N. Volle, J.-L. Pirat, T. Ayad, D. Virieux, RSC Advances 2017, 7, 52101; b) N. Sevrain, J. N. Volle, J. L. Pirat, T. Ayad, D. Virieux, Eur J Org Chem 2018, 2267.

19 a) V. Simonini, M. Benaglia, L. Pignataro, S. Guizzetti, G. Celentano, Synlett 2008, 1061; b) S. Rossi, M. Benaglia, A. Genoni, T. Benincori, G. Celentano, Tetrahedron 2011, 67, 158; c) M. Bonsignore, M. Benaglia, F. Cozzi, A. Genoni, S Rossi, L. Raimondi, Tetrahedron 2012, 68, 8251; d) A. Genoni, M. Benaglia, S. Rossi, G. Celentano, Chirality 2013, 25, 643; e) S. Rossi, R. Annunziata, F. Cozzi, L. Raimondi, Synthesis 2015, 47, 21134; f) S. Rossi, M. Benaglia, R. Cirilli, T. Benincori, Asymmetric Catalysis 2015, 2, 17.

20 For an alternative synthesis of compound $\mathbf{3}$ starting from thiophene see: S. Gabrieli, R. Cirilli, T. Benincori, M. Pierini, S. Rizzo, S. Rossi, Eur J Org Chem 2017, 861.

21 a) T. Benincori, E. Brenna, F. Sannicolò, L. Trimarco , P. Antognazza, E. Cesarotti, F. Demartin, T. Pilati, J. Org. Chem., 1996, 61, 6244; b) T. Benincori, O. Piccolo, S. Rizzo, F. Sannicolò. J. Org. Chem., 2000, 65, 8340.

22 G. A. Kaminski, R. A. Friesner, J. Tirado-Rives, W. L. Jorgensen, J. Phys. Chem. B 2001, 105, 6474.

23 Schrödinger Release 2018-3: MacroModel, Version 11.0; Schrödinger LLC: New York, 2014.

24 S. Gabrieli, G. Mazzeo, G. Longhi, S. Abbate, T. Benincori. Chirality 2016, 28, 686.

25 Gaussian 09, Revision C.01, M. J. Frisch, G. W. Trucks, H. B. Schlegel, G. E. Scuseria, M. A. Robb, J. R. Cheeseman, G. Scalmani, V. Barone, B. Mennucci, G. A. Petersson, H. Nakatsuji, M. Caricato, X. Li, H. P. Hratchian, A. F. Izmaylov, J. Bloino, G. Zheng, J. L. Sonnenberg, M. Hada, M. Ehara, K. Toyota, R. Fukuda, J. Hasegawa, M. Ishida, T. Nakajima, Y. Honda, O. Kitao, H. Nakai, T. Vreven, J. A. Montgomery, Jr., J. E. Peralta, F. Ogliaro, M. Bearpark, J. J. Heyd, E. Brothers, K. N. Kudin, V. N. Staroverov, T. Keith, R. Kobayashi, J. Normand, K. Raghavachari, A. Rendell, J. C. Burant, S. S. lyengar, J. Tomasi, M. Cossi, N. Rega, J. M. Millam, M. Klene, J. E. Knox, J. B. Cross, V. Bakken, C. Adamo, J. Jaramillo, R. Gomperts, R. E. Stratmann, O. Yazyev, A. J. Austin, R. Cammi, C. Pomelli, J. W. Ochterski, R. L. Martin, K. Morokuma, V. G. Zakrzewski, G. A. Voth, P. Salvador, J. J. Dannenberg, S. Dapprich, A. D. Daniels, O. Farkas, J. B. Foresman, J. V. Ortiz, J. Cioslowski, and D. J. Fox, Gaussian, Inc., Wallingford CT, 2010. 

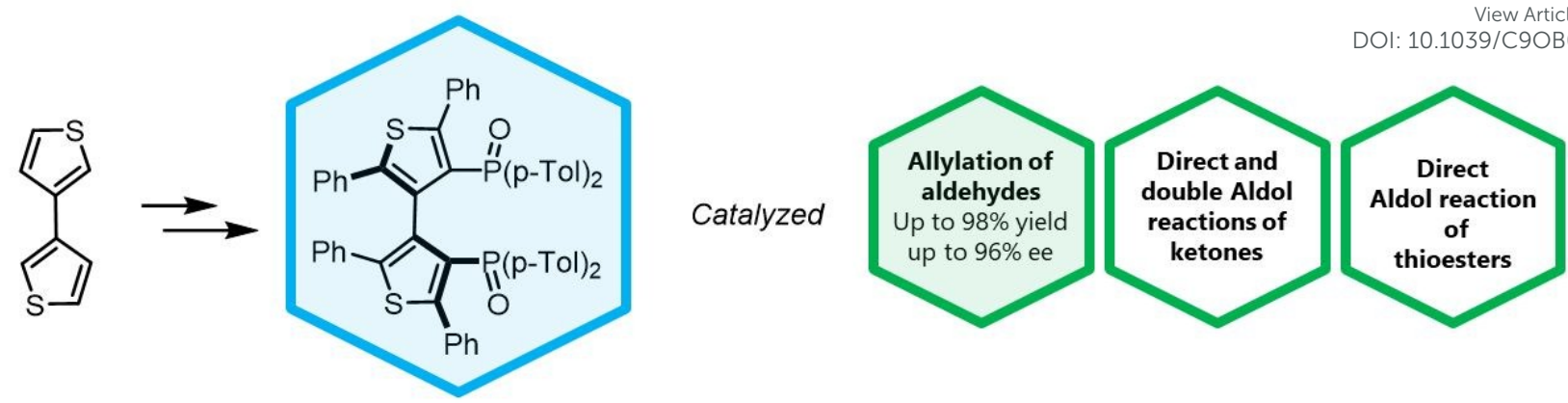

TetraPh-Tol-BITIOPO 